Jorge Alcázar

Facultad de Filosofia y Letras, UNAM

\title{
The Nun's Priest's Tale y sus fuentes a la luz de la sátira menipea
}

Este cuento, proveniente de The Canterbury Tales, es una de las obras de Chaucer más celebradas, empero una de las menos comprendidas en cuanto a su filiación genérica. A veces The Nun's Priest's Tale es considerada tan sólo como una fábula en la que un gallo, Chauntecleer, ha tenido un sueño terrible que raya en la pesadilla. ${ }^{1}$ Allí ve a una bestia, semejante a un perro de caza, que amenaza con quitarle la vida. Al contarle el sueño a su consorte, Pertelote, ésta ve desmoronarse la idea que hasta ese momento tenía de su compañero. Ahora le parece un cobarde, falto de agallas. Chauntecleer interpreta el sueño como un mal augurio; para Pertelote es nada más el efecto de la mala digestión, por lo que prescribe un laxante que ponga fin al problema. Chauntecleer trata de convencerla - con una erudición asombrosa para un ave- de que el sueño vaticina algo malo. Sin embargo, después de tanta palabrería termina por ceder ante los encantos de la dama, con lo cual se va preparando el terreno para el encuentro final con la zorra.

1 Todavía a mediados de la década de 1980, A. C. Spearing, en un artículo introductorio, "The Canterbury Tales IV: Exemplum and fable", pp. 169-172, la concibe en esos términos: "Chaucer's only beast-fable". Helen Cooper hace lo mismo en su Oxford Guide to Chaucer de The Canterbury Tales: "beast-fable [...] a story with a moral in which the animals stand in some kind of exemplary relationship to humans" (p. 340). 
Como apunta un crítico, en vez de que se nos narre llanamente "un día una raposa atrapó a un gallo", el narrador incrementa la trivialidad del evento, según sus propósitos épicoburlescos, al expresar que en un día preciso se produjo lo que podría parecer una tragedia de proporciones cósmicas; una tragedia que además se había predeterminado de antemano en un sueño. ${ }^{2}$ Nadie podría ignorar la presencia de estos elemenn. crtilísticos - asociados con lo que en inglés se denomina mu-heioic - y que sirven para postergar el desenlance de la (b): Con ello se seguirían los principios retóricos de la amplificatio, tal como los presenta Geoffroi de Vinsauf en su Poetria nova, y en particular la conveniencia de dilatar el discurso:

Para que sea más extensa la obra, no pongas los nombres de la cosas: pon otras noticias; no descubras completamente más bien indica el asunto por medio de pequeñas notas; que el discurso no atraviese el asunto, sino, rondándolo con largos ambages, discurre en torno a aquello que tenías que decir brevemente y retarda los tiempos, dando así incremento a las palabras. ${ }^{3}$

Tampoco puede pasar inadvertido el hecho de que Chaucer se valga de una fuente o auctoritas previa. Se ha hablado de tres textos posibles en los que pudo inspirarse: a) la breve fábula de Marie de France, "Del cok e del gupil"; b) los extensos ciclos de historias asociados con el Roman de Renart, en especial la Branche II; c) el todavía más extenso, aunque poco difundido, Renart le Contrefait, cuya Branche VI comparte interesantes particularidades con The Nun's Priest's Tale. De los 38 versos que componen el poema de Marie de France, Chaucer tomó una serie de motivos y elementos léxicos que servirían de

${ }^{2}$ Anne F. Payne, Chaucer and Menippean Satire, p. 132.

${ }^{3}$ Geoffroi de Vinsauf, La poética nueva, (vv. 229-233), p. 9. 
base para el encuentro de Chauntecleer con Daun Russell. ${ }^{4} \mathrm{De}$ la Branche II, compuesta por Pierre de Saint Cloud, habrían salido los motivos principales de la secuencia narrativa (el patio vallado de la finca, el sueño, la discusión, la tentación de cantar con los ojos cerrados, la captura, la persecusión, el escape y la moraleja), tal como están desplegados en el relato de Chaucer. ${ }^{5}$ Sin embargo, en el Roman de Renart es el astuto zorro, una suerte de trickster medieval, quien domina la escena y, por otra parte, recae en Pinte, la gallina, la labor de interpretar con detalle alegórico el sueño de sui compañero.

La tercera fuente, Renart le Contrefait, le proporcionaría al autor inglés ciertos elementos que están ausentes en el otro ciclo. Los personajes confeccionados por el oscuro ćlérigo de Troyes hacen gala de su saber libresco. Por ejemplo, el diálogo en que Renart trata de tentar a Chauntecleer y convencerlo de sus buenos propósitos rebasa la extensión total del cuento de Chaucer, y está salpicado de alusiones a todo tipo de autores. Asimismo, la gallina, quien también tiene por nombre Pinte, se parece a Pertelote en más de un rasgo, ya que (al igual que ella) desecha las implicaciones del sueño de marras y se muestra escéptica sobre su posible trascendencia, burlándose de la cobardía del gallo, a la vez que suelta una andanada sobre el valor de los "consejos femeninos". 6 Como es su costumbre, Chaucer toma algo de aquí y algo de allá, dejando su inequívoca impronta personal, y nos ofrece un relato altamente original que trasciende sus fuentes. Mas no debemos detenernos demasiado en esto, ya que, como se verá más adelante, estos rasgos textuales forman parte de los contextos posibles desde lo cuales es viable aproximamos a esta historia singular, la cual a su vez

${ }^{4}$ Robert A. Pratt, en "Three Old French Sources of the Nonnes Preestes Tale" (p. 443), señala que, de los primeros 26 versos de "Del cok e del gupil", sólo cuatro no tienen su contraparte o eco en la obra de Chaucer.

5 Ibid., p. 444.

6 Ibid., pp. 425-433. 
problematiza el proceso y las posibilidades mismas de cómo interpretarla.

Anne Payne tiene el crédito de ser la primera estudiosa en haber identificado las migas que guarda este relato en verso con la sátira menipea. Siguiendo en parte los argumentos de Bajtín, ella sostiene que en la sátira menipea hay dos aspectos que destacan en especial: su forma dialogada y la parodia de ciertos textos. ${ }^{7}$ Bajtín, por su parte, sitúa a la menipea al lado del diálogo socrático dentro de los géneros cómico-serios que anteceden al desarrollo de la prosa novelesca. Una de las particularidades de la sátira menipea es la de crear situaciones excepcionales en que se pone a prueba la verdad o se confronta la idea filosófica que se tiene de ella. ${ }^{8}$ En esta búsqueda de la verdad es en lo que coincide con el diálogo socrático, en el marco del cual se confrontan diferentes puntos de vista sobre un tema o un problema. ${ }^{9}$

En el universo de la menipea, según lo concibe Bajtín, los personajes se convierten en ideólogos, es decir, se vuelven portavoces de una postura ideológica o filosófica o encarnan en sí mismos una idea. Al entablarse un debate entre dos o más interlocutores, se espera que cada uno induzca al otro a la expresión cabal de su postura. En la obra de Chaucer, encontramos algo semejante cuando Chauntecleer y su gallina preferida se enfrascan en una contienda verbal sobre el alcance del sueño antes referido. Para Chauntecleer el evento onírico presagia

${ }^{7}$ Payne, op. cit., p. 12.

${ }^{8}$ Estos elementos no pasaron inadvertidos por completo para algunos críticos chaucerianos, sin que por ello lograran identificar la inscripción genérica de este cuento. Por ejemplo, Paul G. Ruggiers —n The Art of the Canterbury Tales, p. 193 - apunta: "the context is comic and philosophical. The elevation of Chauntecleer's fortunes to a level we expect of the epic and tragic has the obvious effect of comic incongruity and disproportion"; y el casi siempre atinado Charles Muscatine -en Chaucer and the French Tradition, p. 242- intuye certeramente: "Unlike fable, the Nun's Priest's Tale does not so much make true and solemn assertions about life as it tests truth and tries out solemnities".

${ }^{9}$ Mijań M. Bajtín, Problemas de la poética de Dostoievski, pp. 151-155. 
algo que podría sucederle. Cuando lo contradice su amada, se vale de una erudición bufonesca que raya en la miopía y el monologismo.

Varios de los argumentos esgrimidos por ambas partes provienen del comentario de Robert Holcot, Super Sapientiam Salomonis, como ha detallado Robert A. Pratt en otro extenso artículo. En sus lectiones, dictadas hacia 1335 sobre el texto bíblico, el monje dominico se plantea el problema de si es válida y permisible la adivinación por medio de los sueños. Para lo que él categoriza como sompnia significativa, hay tres posibles causas: a) sueños originados de manera corporal ("ex parte corporis"), por algún humor dominante; b) en la mente ("ex parte anime"), como puede ser la preocupación por un amigo; c) o por el efecto de cuerpos celestes ("ex corporibus celestibus"). Sin embargo, Holcot parece restarle importancia profética a los sueños, al repetir constantemente en sus disertaciones:

Som pnia ne cures, nam fallunt sompnia plures. ${ }^{10}$

El que no haya que preocuparse de los sueños porque son para muchos de nosotros fuente de engaño coincidiría con la postura de Pertelote, quien afirma categóricamente que:

Nothyng, God woot, but vanitee in sweven is.

(VII (B), v. 2922) ${ }^{11}$

Por otra parte, las aprehensiones de Chauntecleer parecen tener un apuntalamiento bíblico, ya que el punto de partida del comentario de Holcot proviene de uno de los libros deuterocanónicos, La sabiduria de Salomón (18. 17-19), donde se habla del castigo divino en contra de los primogénitos de los egipcios, quienes vislumbraron de antemano su destino a través de horribles y aterradoras pesadillas.

${ }^{10}$ Robert A. Pratt, "Some Latin Sources of the Nonnes Preest on Dreams", p. 340.

${ }^{11}$ Sigo el texto editado por Larry D. Benson, The Riverside Chaucer, 1987. 
Para darle peso a sus temores, Chauntecleer apela a todo tipo de autoridades y nos endilga un rosario de exempla. Varios de ellos aparecen en las lecciones de Holcot, cuando éste comenta a autores como Cicerón (De divinatione), Valerio Máximo (Facta et dicta memorabilia) o Alberto Magno (De somno et vigilia). ${ }^{12}$ Entre estos ejemplos se encuentra la historia de dos amigos peregrinos que, al llegar a una ciudad, tienen que separarse para encontrar hospedaje y pasar la noche. Uno de ellos tiene tres sueños. En los dos primeros, su compañero de viaje le asegura que perderá la vida en un establo de bueyes. En el último le dice que ya ha muerto y le da pormenores de dónde se encuentra y quiénes son los culpables del homicidio. En otro semejante, presenta el caso de dos hombres que se embarcan y tienen que detenerse en un lugar en espera de que mejore el viento. Uno de ellos sueña con alguien que, al lado de su cama, le previene que si zarpan se ahogarán. A sabiendas de ello, trata de convencer a su amigo de que desistan de su empresa. Éste no le hace caso y prosigue con su viaje; el barco se va a pique. A estos ejemplos, el gallináceo añade figuras religiosas, bíblicas y literarias, como san Kenelmo, Daniel, José o Andrómaca, que presagia - según se precisa en el Renart le Contrefait, en contradicción con el relato homérico- la muerte de Héctor.

Entre los autores mencionados por Chauntecleer tenemos a Macrobio, quien en su comentario al Sueño de Escipión distingue entre cinco tipos diferentes de sueños. Dentro de esta clasificación, ampliamente conocida en la Edad Media, hay tres clases que tienen trascendencia profética. En primer lugar está el oraculum, en el que aparece una figura piadosa o reverencial, como puede ser un sacerdote, un padre de familia e incluso un dios. En este tipo de sueño se revela algo o se indica qué línea de acción se debe seguir o evitar. El ejemplo del barco hundido es de esta índole. Después tenemos la visión profética o visio,

12 Pratt, "Some Latin Sources of the Nonnes Preest on Dreams", pp. 548-549. 
en la que se vaticina algo que sucederá. Tal es el caso del primer exemplum en que el peregrino es asesinado. En tercer lugar está el sueño enigmático o somnium. Macrobio lo desuribe como aquel que "esconde con formas extrañas y envuelve en la ambigüedad el sentido verdadero de la información ofrecida, y que requiere de una interpretación para comprenderlo". ${ }^{13}$ Y es precisamente un somnium el que deja a Chauntecleer $\tan$ inquieto y temeroso.

This Chauntecleer gan gronen in his throte, As man that in his dreem is drecched soore. And whan that Pertelote thus herde hym roore, She was agast, and seyde, "Herte deere, What eyleth yow, to grone in this manere? Ye been a verray sleper; fy, for shame!" And he answerde, and seyde thus: "Madame, I pray yow that ye take it nat agrief. By God, me mette I was in swich meschief Right now that yet myn herte is soore afright. Now God," quod he, "my swevene recche aright, And kepe my body out of foul prisoun! Me mette how that I romed up and doun Withinne our yeerd, wheer as I saugh a beest, Was lyk an hound, and wolde han maad areest Upon my body, and wolde han had me deed. His colour was bitwixe yelow and reed, And tipped was his tayl and bothe his eeris With blak, unlyk the remenant of his heeris; His snowte smal, with glowynge eyen tweye. Yet of his look for feere almoost I deye;

This caused me my gronyng, doutelees."

(VII (B), vv. 2886-2907) ${ }^{14}$

13 Macrobius, Commentary on the Dream of Scipio, pp. 87-90.

14 Transcribo la traducción en prosa de Pedro Guardia, en la edición de Cátedra:

Chantecler [...] empezó a gemir como un hombre que tiene una maligna pesadilla cuando duerme. Al oír Pertelote aquel alboroto se asustó y exclamó: 
El debate en que se enfrasca esta pareja obedece a ópticas divergentes. La dama, a diferencia de Chauntecleer, busca una explicación natural a tal suceso. Los remedios que ofrece parecen representar el punto de vista de la experiencia práctica. ${ }^{15}$ Semejante sueño se debe a una ingestión exagerada — síntoma que concuerda con una de las variedades macrobianas de la pesadilla (insomnium) - o bien puede responder a un desbalance de los humores que circulan por el cuerpo. Para dar razón de esto último, Pertelote nos ofrece una explicación cromoterapeútica que, siguiendo el principio de que lo semejante atrae lo semejante, nos previene sobre el exceso de bilis, ya sea roja o negra, en el cuerpo. Esta clase de saber popular (lore) no parece ser del agrado de Chauntecleer, quien le confiere mayor valía al conocimiento libresco, lo cual en sí no garantiza de ninguna manera que pueda entender mejor el alcance del sueño enigmático, puesto que su contenido onírico — que pide de una lectura alegórica, como indica C. S. Lewis- ${ }^{16}$ permanece en una penumbra sígnica que a final de cuentas resulta inaccesible para el amo y señor del gallinero.

Para Anne Payne, como para otros comentaristas, lo que está en el fondo de todo es una parodia de las diversas disquisiciones filosóficas - vigentes en el Medievo- sobre la predes-

- Corazón, cariño, ¿qué te pasa? ¿Por qué gimes así? ¡Vaya dormilón estás hecho! Deberías avergonzarte.

Chantecler replico:

- Por favor, no te preocupes. Soñaba que estaba ahora mismo en un aprieto tal, que mi corazón todavía está temblando de miedo. ¡Ojalá Dios haga propicio mi sueño y libre mi cuerpo de entrar en una sucia mazmorra! Pues soñe que mientras paseaba de un lado a otro por nuestro patio vi a una criatura parecida a un perro, con ademán de agarrarme y hacerme pasar a mejor vida. Tenía el color amarillo rojizo, pero la punta de la cola y las orejas eran negras, al revés que el resto de su pelo; tenía un hocico estrecho y dos ojos de mirada penetrante. Todavía estoy medio muerto de miedo por su aspecto. No es extraño que gimiera. (p. 486)

15 Ruggiers (op. cit., p. 189) la caracteriza en estos términos: "Her wisdom is for the most part the wisdom of the home dispenser".

${ }^{16}$ C. S. Lewis, The Discarded Image, p. 63. 
tinación y el libre albedrío. ${ }^{17}$ En primer lugar tenemos la postura determinista del obispo Bradwardine, quien hace hincapié en el alcance del control divino sobre el destino de los hombres, reduciendo prácticamente a cero la libertad de éstos, al considerarlos como mera extensión de la voluntad de Dios. Después está la posición conciliatoria de san Agustín, en la que coexisten - en una concomitancia paradójica que sólo puede ser abonada por la fe- la voluntad humana y la presciencia divina: uno actúa como quiere, Dios sabe de antemano que así se hará. Por último se encuentran los planteamientos de Boecio, que constituyen una variante de los de san Agustín. Su aportación consiste en poder formular la diferencia entre necesidad simple y condicional, tal como puede encontrarse en el último libro de La consolación de la filosofía, obra que Chaucer, por cierto, vertió al inglés.

Boecio postula que Dios vive en un eterno presente, en el que ve de manera simultánea el curso infinito del pasado y el futuro. Esta mirada divina, que es más bien providente que previdente, distingue claramente entre los hechos que llevan en sí la necesidad de producirse, como la salida del sol, y aquellos que dependen de la libre facultad del agente. Dentro de los que pertenecen a la primera categoría se puede hacer una diferenciación:

Hay dos clases de cosas necesarias: unas que lo son absolutamente, como el que los hombres sean mortales; otras son condicionalmente necesarias, como el hecho de que uno ande, cuando con certeza se sabe que está andando. Porque si se conoce un hecho, éste no puede menos de ser como se conoce; pero esto no implica necesidad absoluta de que el hecho exista. En tal caso, la necesidad no viene de la naturaleza del hecho sino de una condición o circunstancia que a él se agrega; porque ya se comprende que nada hay que obligue a un hombre a

${ }^{17}$ Chaucer and-Menippean Satire, pp. 159-180. 
caminar cuando lo hace voluntariamente, aunque cuando está caminando, necesariamente se verifica el hecho de que camine. Del mismo modo, si la Providencia ve un hecho en el presente, necesariamente se ha de dar tal hecho, aunque por su naturaleza no implique ninguna necesidad. Ahora bien, Dios ve simultáneamente presentes los futuros libres; los cuales, por consiguiente, con relación a la mirada divina son necesarios, por ser conocidos por la ciencia de Dios; pero considerados en sí mismos, no pierden el carácter de libres, propio de su naturaleza. ${ }^{18}$

En la exposición de la Filosofía se hallan entreverados varios de los giros posibles de la trama de este cuento, que pueden conducir a Chauntecleer o desviarlo del encuentro providencialmente proyectado con la bestia misteriosa. Por otra parte, cabe añadir que Payne considera, asimismo, que lo que subyace a todo este despliegue de sapiencia libresca es el escamoteo $u$ ocultamiento de un hecho inequívoco: el que Chauntecleer debería encarar su posible muerte en las fauces del zorro. ${ }^{19}$

Ahora bien, no está de más tener en cuenta las previsiones sugeridas por otro comentador. Ian Bishop ha señalado que este cuento pone en un primerísimo plano su carácter textual, y esto debiera alertar al crítico que trata de desentrañar su significado a estar en guardia permanente ante una obra que esgrime como blanco satírico el acto mismo de la interpretación. ${ }^{20} \mathrm{Y}$ aquí entramos a la dimensión alegórica del texto, ya que un relato que juega con las convenciones de la fábula debería rebasar los confines en que habitan este gallo - de erudición poco menos que universitaria o clerical-y las hembras que integran su harén.

Este rasgo multidimensiona el cuento del capellán o, si se prefiere el término usado por Dante en la Epístola XIII, lo hace

18 Boecio, La consolación de la filosofía, pp. 215-216.

${ }^{19}$ Chaucer and Menippean Satire, p. 181.

${ }^{20}$ Ian Bishop, The Narrative Art of the Canterbury Tales, p. 164. 
polisémico. Esta proyección a varios niveles la podemos observar desde los contornos que enmarcan el relato. El gallo y sus siete concubinas parecen formar un universo en sí mismo, lo cual sería una especie de carnavalización del sistema planetario. Chantecleer, además de cantar con exactitud de relojero, conoce los grados y la posición del sol. Por encima de este nivel, tenemos el mundo de la granja, comandado por la viuda y sus hijas y las virtudes que las acompañan como son la frugalidad y el decoro. En este nivel, los indicios del sueño que permanecen en una suerte de penumbra enigmática y que no pueden ser identificados por Chauntecleer, serían claramente decodificables para los habitantes de este perímetro del cosmos, como se demuestra al final cuando todos persiguen al zorro depredador.

Esta dimensión queda claramente emblematizada hacia la mitad del cuento. A esa altura de la historia, después de las sesudas disquisiciones sobre los sueños, Chantecleer hace gala de su buen latín, al traducir el lugar común misógino Mulier est hominis confusio por "Womman is mannes joye and al his blis". Con este gesto no hace otra cosa sino sucumbir y anticipar lo que hará la raposa con él: valerse del halago y la adulación para conseguir sus propósitos. ${ }^{21} \mathrm{La}$ belleza y el encanto de la hembra hacen que sus temores desaparezcan y que se manifieste desafiante ante las visiones y pesadillas ominosas. $Y$ acto seguido se entrega a los placeres de la carne, copulando repetidas veces con Pertelote:

He fethered Pertelote twenty tyme, And trad hire eke as ofte, er it was pryme.

(VII (B), vv. 3177-3178) 22

${ }^{21}$ Esto es lo que Charles A. Owen denomina "deceitful flattery" en su artículo "The Crucial Passages in Five of The Canterbury Tales", p. 264.

22 [...] emplumó a Pertelote veinte veces y la montó otras tantas, antes de terminar el día. (p. 492) Ya que se menciona la hora prima, tal vez no esté de más tener presente la parodia que se hace de las horas canónicas en el Libro de Buen 
Aquí encontramos una de las tensiones temáticas que se despliegan a lo largo y ancho de The Canterbury Tales. Me refiero a la oposición entre los impulsos sublunares y los deseos trascendentes, polos virtuales en los que se mueven varios de los peregrinos y personajes de este gran tapiz social y literario. En un renombrado ensayo, Arthur W. Hoffman recalcaba esta tensión identificable desde los versos iniciales, en la descripción de la primavera con la que abre la obra, donde se funden y van de la mano el tiempo de la procreación (el falocentrismo del aire que impregna la tierra) y del peregrinaje a un santuario religioso, como el de Thomas Becket. Estos impulsos encontrados están emblematizados por el broche dorado que ostenta la priora, en el que se puede leer: Amor vincit omnia. Lo que da a pensar a qué tipo de amor alude el mote, $i$ al amor divino o al mundano? $O$ también lo podemos ver en el bulero enunuco que se desvive por los placeres de la carne y quien, sin embargo, es capaz de conducir, con su postura cínica y su elocuencia retórica, a los hombres al arrepentimiento. ${ }^{23}$ Chauntecleer parece seguir impulsos semejantes. Por un lado se preocupa por descifrar los designios celestes que pueden estar cifrados y escondidos en los sueños; por el otro, con el solaz y la tranquilidad que le proporciona su compañera, no desaprovecha la oportunidad de entregarse a la pulsión genital y a la cópula desmedida, que no significaría otra cosa sino seguir tan sólo la voz de la especie o circunscribirse, en términos de Boecio, a los mandatos de la necesidad simple.

En ese momento el capellán interrumpe la narración y, aun cuando se lava las manos, aduciendo que su historia trata tan sólo de un gallo que se desentiende del consejo de su mujer, siembra la semilla alegórica insinuando:

Amor (372-387), en el que el autor, valiéndose de citas bíblicas fuera de contexto, hace más palpable el abismo que mediaba entre la vocación religiosa y el imán de los placeres y los amores terrenales.

${ }^{23}$ Arthur A. Hoffman, "Chaucer's Prologue to Pilgrimage: The Two Voices", pp. 30-45. 
Wommennes conseils been ful ofte colde;

Wommannes conseil broghte us first to wo,

And made Adam fro Paradys to go,

Ther as he was ful myrie and wel at ese.

But for I noot, to whom it myght displese,

If I conseil of wommen wolde blame,

Passe over, for I seyde it in my game.

Rede auctours, where they trete of swich mateere,

And what thay seyn of wommen ye may heere.

(VII (B), vv. 3256-3264) $)^{24}$

Con esta insinuación la triada Chauntecleer-Pertelote-zorro se puede transformar figurativamente en Adán-Eva-serpiente. Y puesto que el fatal encuentro con el zorro tiene lugar un viernes —el día en que preponderan astrológicamente las inclinaciones amorosas y venusinas - pero también, a su vez, el mismo día en que falleció el rey Ricardo Corazón de León, cuyo derecho divino lo hermana con el prototipo de todos los sacrificios, se abre el portal de una semiosis infinita, que termina de manera provisional cuando el narrador de hábitos religiosos remata su intervención, invitándonos a meditar sobre la moraleja del relato, y nos pide que desbrocemos el grano de la crústula que la cubre.

But ye that holden this tale a folye,

As of a fox, or of a cok and hen,

Taketh the moralite, goode men.

For Seint Paul seith that al that writen is,

To oure doctrine it is ywrite, ywis;

Taketh the fruyt, and lat the chaf be stille.

(VII (B), vv. 3438-3443) ${ }^{25}$

${ }^{24}$ Los consejos de las mujeres suelen ser fatales. El primer consejo de mujer nos trajo a todos dolor e hizo que Adán fuera expulsado del Paraíso en el que era tan feliz y estaba tan cómodo. Pero pasemos esto por alto, pues no quiero ofender a nadie al despreciar los consejos femeninos. Lo digo en broma. Leed los autores que tratan el tema y sabréis lo que tienen ellos que contar sobre las mujeres. (p. 494)

${ }^{25}$ Amigos míos, si creéis que esta historia no es más que una farsa que concierne [a una zorra,] un gallo y una gallina, recordad la moraleja. San Pablo dice que 
Y aquí podríamos ver la diferencia, en términos de la materia prima narrada, entre la postura del capellán y el párroco cuya intervención cierra el opus magnum de Chaucer. Del primero hay escasa información en el Prólogo General; en cambio al segundo se le presenta desde un ángulo de encomio implícito: es humilde pero virtuoso, uno de los paradigmas de la verdadera nobleza y de la pureza humana ("clennesse"), quien además predica con el ejemplo. No obstante ser un clérigo ("a lerned man, a clerk"), se declara poco sofisticado — por lo que toca a cuestiones retóricas- cuando el anfitrión de este peregrinaje le pide que cuente una historia.

Thou getest fable noon ytoold for me;

For Paul, that writeth unto Thymothee,

Repreveth hem that weyven soothfastnesse,

And tellen fables and swich wrecchednesse.

Why sholde I sowen draf out of my fest,

Whan I may sowen whete, if that me lest?

For which I seye, if that yow list to heere

Moralitee and vertuous mateere,

And thanne that ye wol yeve me audience,

I wol ful fayn, at Cristes reverence,

Do yow plesaunce leefful, as I kan.

$(\mathrm{X}(\mathrm{I}), \mathrm{vv} \cdot 31-41)^{26}$

En dos textos tan disímbolos se recurre a la misma analogía: el sentido recóndito en el interior del grano. Esto es moneda

todo lo que está escrito, lo está para nuestra instrucción y educación. Por tanto, tomad el grano y dejad la paja. (p. 498)

26 -No conseguiréis fábulas de mi -replicó el párroco-. Pues, en su Epístola a Timoteo, Pablo riñe a los que se apartan de la verdad y cuentan fábulas y tonterias así. ¿Por qué mi mano debe sembrar la broza cuando lo que deseo es poder sembrar el grano de trigo? Por tanto, digo que, si queréis oír algún asunto moral y edificante y estáis dispuestos a prestarme atención, entonces tendré sumo gusto, con la bendición de Cristo, en daros el placer legítimo que pueda. (p. 554) 
corriente en la literatura medieval, el que a menudo se proponga un significado ulterior o una comprensión figurada. Y esta metáfora de la corteza que recubre el sentido profundo todavía la podemos encontrar ya bien entrado el Renacimiento. Por ejemplo, León Hebreo en su Diálogos de amor (1535) plantea que "los poetas encierran muchos sentidos en sus ficciones", recurriendo a términos semejantes como "la corteza exterior" (sentido literal) que recubre los "sentidos medulados", también llamados alegóricos. ${ }^{27}$

Ahora si comparamos la posición de los dos narradores chaucerianos, encontraremos actitudes enteramente divergentes que rebasan la aceptación tácita, como hemos visto, de que la alegoría es parte integral de la obra poética. Para el párroco no existe otra función sino la didáctica o edificante, como lo constata el extenso sermón que nos ofrece en lugar del cuento esperado por el resto de los peregrinos. En cambio el relator de The Nun's Priest's Tale hace una fusión magistral de la idea filosófica y el entretenimiento literario, por lo que podría ser un buen candidato -en el caso de que el viaje de ida y vuelta hubiera llegado a feliz término- para quedarse con el premio prometido por Harry Bailly. El dueño de la hostería ponía como condición que el ganador de la justa narrativa:

And which of yow that bereth hym best of alle-

That is to seyn, that telleth in this caas

Tales of best sentence and moost solaas-

Shal have a soper at oure aller cost

(I (A), vv. 796-799 $)^{28}$

Aquí "sentence" sugiere, como apunta C. S. Lewis, no solamente significado o contenido, sino algo que es en sí significa-

${ }^{27}$ León Hebreo, Diálogos de amor, pp. 77-78.

${ }^{28} \mathrm{El}$ que relate su historia mejor - con el argumento más edificante y divertido- será obsequiado con un banquete a costa del resto del grupo. (p. 86) 
tivo, que tiene "depth of meaning", como se dice del clérigo cuya vocación son los libros en el Prólogo General: "ful of hy sentence" (I (A), v. 306). ${ }^{29}$

Para terminar, sólo quisiera apuntar lo siguiente. Si como hemos visto, la sátira menipea es un género dinámico y proteico, el cual exhibe una marcada exploración de las posibilidades indagatorias de aquello que nos mueve a la risa, tal vez debiéramos haber comenzado preguntándonos por la situación inicial que dispara la comicidad ulterior de The Nun's Priest's Tale. Me refiero al hecho palpable y elemental de que un par de aves se hayan agenciado el don de la palabra. En el cuento se nos da a entender que en un pasado indefinido, una suerte de edad de oro, los animales hablaban; lo cual de nuevo nos remitiría a la multiplicidad de planos mencionados antes.

Rasgo semejante nos sugiere otro par de obras en que unos animales discurren sobre todo tipo de cosas. Aquí tengo en mente, en primera instancia, el diálogo de Luciano de Samosata, El sueño o El gallo. ${ }^{30}$ En esta obrita, el canto prematuro del gallo interrumpe un grato sueño, en que Micilo se veía rodeado de riquezas.: El pobre hombre quisiera ahorcar al animal, pero se detiene cuando éste le dirige la palabra. Para asombro del zapatero, no sólo le habla sino además le da razones, algunas de tipo práctico, otras de índole literaria y orden filosófico o libresco. Micilo se pregunta si es que todavía estará soñando. Y como sorpresa mayor, el gallo admite ser ni más ni menos que la reencarnación del mismísimo Pitágoras. Ante semejante revelación el pobre operario no puede sino admitir que se en-

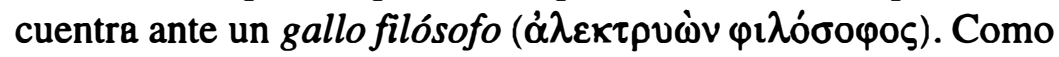
es de imaginarse, el ave es capaz de disertar, de forma metaonírica, sobre la naturaleza y función de los sueños, ya sea alu-

29 C. S. Lewis, Studies in Words, pp. 139-140.

${ }^{30}$ Kirk, en su catálogo bibliográfico, coloca este diálogo (con el número 136 de su inventario) entre las obras de Luciano en que no cabe duda de que pertenecen a la menipea. $C f$. su Menippean Satire, p. 16. 
diendo a Homero o algún otro escritor. ${ }^{31}$ Se antoja como algo tentador sugerir este texto como otra fuente posible del relato de Chaucer, pero esto requeriría hacer una indagación en torno a la posible recepción medieval de Luciano, lo cual rebasa con creces los límites del presente trabajo.

Lo que sí podemos hacer es referirnos a otro texto semejante, con lo cual se irán delineando ciertos rasgos intertextuales de la menipea. En El coloquio de los perros, una noche Cipión y Berganza caen en la cuenta de que no sólo hablan, lo cual rebasa los término fijados por la naturaleza (como es el caso del gallo precedente), sino que hablan asimismo con discurso razonado. Si en la obra de Chaucer hay una parodia de la docta disquisición sobre la interpretación de los sueños -como igualmente ocurre con el diálogo lucianesco- también en la novela de Cervantes nos encontramos con un reacomodo dialógico y polivocal que juega e ironiza los géneros intercalados. Éstos abarcan desde aquellos provenientes del saber gnómico (el conocimiento de un hombre educado de la época, ya sea en la vertiente del diálogo erasmiano o diversas disertaciones sobre el mundo de las brujas, los matemáticos o los arbitristas) hasta la confesión y la novela picaresca, ya que el discurso de vida que nos ofrece Berganza - con su disposición amorfa y episódica- alude intertextualmente al género picaresco, habiendo incluso lugar para manipular lúdicamente las convenciones de otros géneros como el pastoril y el entremés. Mientras que en el caso del segundo personaje, Cipión, tenemos a un individuo bastante versado en los sentidos alegóricos que un texto puede implicar, lo cual es una invitación tácita a leer la obra a varios niveles. ${ }^{32}$ Así esta novela ejemplar cervantina se mueve entre los polos activos de "murmurar" - eufemismo que sirve para significar la sátira de las costumbres del momento- y "filoso-

31 A. M. Harmon, ed., Lucian, vol. II, pp. 171-239.

32 Miguel de Cervantes, Novelas ejemplares, vol. II, pp. 299-359. 
far", el propósito edificante implícito en cualquier texto literario, polos naturales de los géneros cómico-serios como los ha definido Bajtín.

Esta dimensión dialógica y transtextual (por lo que toca a las tres obras) responde a ciertos principios bajtinianos asociados con la menipea. En primer término, se asume que por medio de la aventura y "la fantasía más audaz e irrefrenable" se crean "situaciones excepcionales para provocar y poner a prueba la idea filosófica, la palabra, y la verdad plasmada en la imagen del sabio buscador de esta verdad", ${ }^{33}$ ya sea éste un can o un gallo, o en el caso de Chauntecleer: un personaje que hace gala de una erudición que raya en lo bufonesco, como hemos tratado de documentar a lo largo de este artículo. Y tal vez más importante aún sea el hecho de que, al considerar la cuestión de las fuentes posibles del relato de Chaucer, éstas pierdan el valor tradicional que se les asigna en la investigación filológica.

Aquí pasa a un segundo plano la cuestión del origen mismo de las fuentes. Ahora lo que vemos es una trama de voces que provienen de los sitios más diversos: el discurso formal del conocimiento, las estrategias retóricas de la composición literaria, las modalidades de la cultura y el saber popular, así como las disquisiciones teológicas; habiendo lugar al final del texto para hacer mención - por medio de una textura estilística que raya en lo cacofónico- de la revuelta campesina que tuvo lugar en 1381. Como apunta Wetherbee la alusión a Jack Straw (v. 3394), uno de los lideres de un levantamiento que buscaba entre otras cosas poner fin al vasallaje de los campesinos, establece un contrapunto elocuente con la referencia previa a Ricardo Corazón de León, creando una oposición entre el material idealizado propio de las leyendas y la autenticidad inmediata de un hecho real. ${ }^{34}$ Este carácter de actualidad inmediata también es

${ }^{33}$ Bajtín, Problemas de la poética de Dostoievski, p. 161.

34 Winthrop Wetherbee, Geoffrey Chaucer: The Canterbury Tales, p. 120. 
un rasgo definitorio de la menipea, como señaló Bajtín en su momento. ${ }^{35}$ Lo cual enriquece y complica las capas contextuales de la obra, si tomamos en cuenta que la apariencia verbal cacofónica de dicha alusión es en sí mismo un gesto paródico que se vale de un pasaje latino de John Gower en Vox Clamantis. ${ }^{36}$ Con todos estos elementos en mente, ahora podemos estar en condiciones de identificar un amplio cruce e intersección de voces y discursos - como acabamos de señalar- provenientes de las esferas más diversas del quehacer humano. Por lo tanto, hemos cobrado conciencia de que en una producción poética como la de Chaucer, la palabra (el discurso en su sentido más general), parece haberse convertido en el espacio ebulliciente por excelencia donde se dirimen todo tipo de cuestiones serias, cómicas, políticas o filosóficas.

\section{Bibliografía}

Bajtín, Mijaíl M., Problemas de la poética de Dostoievski, México, Fondo de Cultura Económica, 1986.

Benson, Larty D., ed., The Riverside Chaucer, Boston, Houghton Mifflin, 1987.

Bishop, Ian, The Narrative Art of the Canterbury Tales, Londres, Dent, 1987.

Boecio, La consolación de la filosofía, Madrid, Sarpe, 1985.

Cervantes, Miguel de, Novelas ejemplares, vol. II, ed. de Harty Sieber, Madrid, Cátedra, 1985.

COOPER, Helen, The Canterbury Tales (Oxford Guides to Chaucer), 2a. ed, Oxford, Oxford University Press, 1996.

Chaucer, Geoffrey, Cuentos de Canterbury, trad. de Pedro Guardia, Madrid, Cátedra, 1999.

Harmon, A. M., ed., Lucian, vol. II, Londres, Heinemann, 1953 (The Loeb Classical Library).

35 Problemas de la poética de Dostoievski, p. 167.

${ }^{36}$ Cf. Bishop, op. cit., pp. 170-171. 
Hebreo, León, Diálogos de amor, México, Pornúa, 1985.

Hoffman, Arthur A., "Chaucer's Prologue to Pilgrimage: The Two

Voices", en Edward Wagenknecht, ed., Chaucer: Modern Essays in Criticism, Londres, Oxford University Press, 1959, pp. 30-45.

KIRK, Eugene P., Menippean Satire: An Annotated Catalogue of Texts and Criticism, Nueva York, Garland, 1980.

Lewis, C. S. The Discarded Image, Cambridge, Cambridge University Press, 1964.

—, Studies in Words, Cambridge, Cambridge University Press, 1967.

Macrobius, Commentary on the Dream of Scipio, ed. de William Harris Stahl, Nueva York, Columbia University Press, 1952.

Muscatine, Charles, Chaucer and the French Tradition, Los Angeles, The University of California Press, 1957.

Payne, Anne F., Chaucer and Menippean Satire, Madison, Wis., University of Wisconsin Press, 1981.

PratT, Robert A., "Three Old French Sources of the Nonnes Preestes Tale", Speculum, 47, 1972, pp. 422-444, 646-668.

- "Some Latin Sources of the Nonnes Preest on Dreams", Speculum, 52, 1977, pp. 538-570.

SPEARING, A. C. "The Canterbury Tales IV: Exemplum and fable", en Piero Boitani and Jill Mann, eds., The Cambridge Chaucer Companion, Cambridge, Cambridge University Press, 1986, pp. 159-177.

Owen, Charles A., "The Crucial Passages in Five of The Canterbury Tales: A Study in Irony and Symbol", en Edward Wagenknecht, ed., Chaucer: Modern Essays in Criticism, Londres, Oxford University Press, 1959, pp. 251-270.

Ruggiers, Paul G., The Art of the Canterbury Tales, Madison, Wis., University of Wisconsin Press, 1965.

Vinsauf, Geoffroi de, La poética nueva, trad. Carolina Ponce, México, UNAM, 2000.

Wetherbee, Winthrop, Geoffrey Chaucer: The Canterbury Tales, Cambridge, Cambridge University Press, 1989. 